\title{
TINGKAT OKSIGEN DALAM DARAH TERHADAP KEJADIAN CARDIAC ARREST PADA PASIEN CIDERA KEPALA BERAT
}

\author{
Winanda Rizki Bagus Santosa ${ }^{1}$, Erry Arisma ${ }^{2}$ \\ Fakultas Kesehatan Program Studi S1 Keperawatan Institut Ilmu Kesehatan Bhati \\ Wiyata Kediri \\ Jalan Wachid Hasyim No.65 Bandar Lor, Kecamatan Mojoroto, Kota Kediri, Jawa Timur, \\ Indonesia \\ winandarizky@gmail.com, queenerry31@gmail.com
}

\begin{abstract}
Abstrak
Penyebab terbanyak dari cidera kepala berat adalah kecelakaan kendaraan bermotor dan jatuh dari ketinggian yang menyebabkan cardiac arrest. Cardiac arrest mengakibatkan pasien tidak sadarkan diri, tidak ada nafas, dan tidak ada nadi. Kejadian cardiac arrest sebagian besar karena pasien mengalami hipoksia. Pasien cidera kepala berat ditandai dengan Gasglow Coma Scale (GCS) 8 atau kurang. Pasien dengan cidera kepala berat sering mengalami penurunan tingkat oksigen dalam darah dan harus memerlukan definitive airway untuk mencegah terjadinya cardiac arrest. Penelitian ini bertujuan untuk mengetahui tingkat oksigen dalam darah terhadap kejadian cardiac arrest pada pasien cidera kepala berat. Penelitian dilakukan di RSUD Gambiran Kota Kediri. Penelitian korelasional dengan pendekatan cross sectional. Sampel penelitian ini sejumlah 18 responden. Teknik pengambilan sampel adalah total sampling. Uji statistik penelitian ini adalah Spearman's rho. Hasil penelitian ini nilai $\mathrm{p}=0,035$ yang berarti $\mathrm{p}<\alpha(\alpha=0,05)$. Ada hubungan tingkat oksigen dalam darah terhadap kejadian cardiac arrest pada pasien cidera kepala berat.
\end{abstract}

Kata Kunci : Tingkat Oksigen Dalam Darah, Cardiac arrest, Cidera Kepala Berat

\begin{abstract}
The most common causes of severe head injuries are motor vehicle accidents and falls from a height that cause cardiac arrest. Cardiac arrest resulted in the patient being unconscious, no breathing, and no pulse. The incidence of cardiac arrest is mostly because the patient is hypoxic. Patients with severe head injuries are characterized by a Gasglow Coma Scale $(G C S)$ of 8 or less. Patients with severe head injuries who often have decreased oxygen saturation should require a definitive airway to prevent patient death. This study aims to determine the level of oxygen in the blood on the incidence of cardiac arrest in patients with severe head injury. The research was conducted at Gambiran Hospital, Kediri City. Correlational research with cross sectional approaches. The sample of this research is 18 respondents. The sampling technique is total sampling. The statistical test of this research is Spearman's rho. The results of this study $p$ value $=0.035$ which means $p<(\alpha=0.05)$. There is a relationship between the level of oxygen in the blood and the incidence of cardiac arrest in patients with severe head injury.
\end{abstract}

Keywords: Blood Oxygen Level, Cardiac arrest, Severe Head Injury.

\section{PENDAHULUAN}

Cidera kepala berat merupakan trauma mekanik pada kepala yang terjadi baik secara tidak langsung atau langsung yang dapat mengakibatkan masalah fungsi neurologis, gangguan fisik, gangguan kognitif, gangguan psikososial yang bersifat permanen yang ditandai dengan Gasglow Coma Scale (GCS) $\leq$ 8 (Mauritz, 2008). Cidera kepala berat penyebab utama cardiac arrest serta peningkatan biaya ekonomi di dunia. Cidera kepala berat disebabkan karena gangguan langsung dari jaringan otak yang terjadi akibat traumatis dan disfungsi otak atau kerusakan sel (Dinsmore, 2013). Tanda pasien mengalami cardiac arrest adalah tidak ada nafas, tidak ada nadi, dan hilang kesadaran (Smith, 2015)

Negara Eropa, termasuk Denmark, Swedia, Finlandia, Portugal, Jerman ,Swedia, Italia, Swiss, Spanyol, Irlandia, Inggris, dan,

Corresponding author:

Winanda Rizki Bagus Santosa

winandarizky@gmail.com 
Perancis, rasio keparahan cidera kepala berat pasien rawat inap adalah banyak sekali. Angka kematian rata-rata sekitar 11 per 100 orang per hari (Jiang, 2013). Sejumlah faktor yang diyakini memengaruhi pasien trauma kepala adalah usia, jenis kelamin, Glasgow Coma Scale (GCS), tekanan intrakranial (ICP), ukuran pupil, dan hipoksia (Dinsmore, 2013).

Lebih dari 2 juta orang Cina setiap tahun mengalami cidera kepala, seperempat di antaranya memerlukan rawat inap dan $15 \%$ dari mereka mengalami gangguan fisik, kognitif, perilaku, dan gangguan psikososial. Angka kematian cidera kepala signifikan menurun selama 30 tahun terakhir dari sekitar $40 \%$ menjadi $25 \%$ dan lebih rendah karena perbaikan dalam managemen di Negara Cina (Jiang, 2013).

Negara Indonesia kasus kejadian cidera kepala sebanyak $8,2 \%$ dan kejadian yang paling banyak di Sulawesi tengah $12.8 \%$ dan kejadian paling sedikit berada di Jambi $4,5 \%$. Jawa timur kasus kejadian cidera kepala sebanyak $7,7 \%$ yang paling banyak disebabkan karena kecelakaan sepeda motor sebanyak $(40,1 \%)$ (Trihono, 2013).

Setiap tahunnya dari $80 \%$ semua pasien cedera kepala telah menderita trauma kepala ringan dengan GCS 14-15. Jumlah ini mungkin dianggap banyak karena pasien mengalami cidera kepala sedang dengan GCS 9-13 sejumlah $10 \%$, sedangkan $10 \%$ memiliki cedera kepala berat dengan GCS $\leq 8$. Semua cardiac arrest trauma berasal dari cedera kepala berat. Paling banyak penyebab cedera kepala adalah jatuh dan kecelakaan kendaraan bermotor. Cedera otak dapat diklasifikasikan menjadi dua bagian yaitu primer dan sekunder. Cedera otak primer adalah gangguan langsung dari jaringan otak yang terjadi akibat traumatis. Cedera sekunder adalah disfungsi otak atau kerusakan sel (Moppett, 2007).

$$
\text { Banyak faktor yang dapat }
$$

menyebabkan cedera. Sering kali pasien jatuh terjadi cidera. Sebuah survei primer untuk menilai cidera kepala berat dapat menggunakan airway, breating, sirkulasi. Hal ini penting untuk mencegah hipoksia pada pasien dengan cedera kepala karena merupakan penyebab umum dari cedera otak sekunder. Penyebab sekunder cidera otak adalah hipotensi, hipoksia, anemia, hipo/hyperkalemia, hipertensi, edema serebral, dan kejang yang dapat memyebabkan cardiac arrest jika tidak diberikan penanganan dengan tepat ( $\mathrm{Ji}$ Yao Jiang et al, 2013).

Pasien cidera kepala berat saat terjadi penurunan tingkat kesadaran biasanya akan diberikan bantuan airway dengan membuka jalan nafas menggunakan naso/orofaringeal, endotraheal tube, laryng mask airway, ventilator, dan definitif airway lainnya. Alat ini akan membantu proses respirasi pasien, sehingga oksigen benar-benar masuk ke paruparu. (Wesson, 2015). Pemantauan tanda tanda vital dan kadar tingkat oksigen dalam darah menggunakan alat pulse oximetri. Tingkat oksigen dalam darah pada pasien cidera kepala berat adalah naik turun tergantung kondisi pasien, semakin tinggi nilai tingkat oksigen dalam darah pasien maka kondisi pasien akan lebih stabil dan angka kehidupan juga lebih tinggi. Pemantauan nilai tingkat oksigen dalam darah yang benar dan tepat akan menurunkan risiko hipoksemia (Afiani, 2021).

Tujuan dari penelitian ini adalah untuk menganalisis tingkat oksigen dalam darah terhadap kejadian cardiac arrest pada pasien cidera kepala berat.

\section{METODE PENELITIAN}

Metode penelitian ini adalah korelasional. Penelitian ini dilakukan dengan menggunakan pendekatan cross sectional yaitu pengumpulan data dengan observasi, atau pengumpulan data pada satu saat.

Penelitian ini telah dilaksanakan di ruang ICU RS Gambiran kota kediri selama satu bulan. Populasi penelitian ini seluruh pasien cidera kepala berat diruang ICU yang sedang terpasang ventilator. Sampel penelitian pasien cidera kepala berat diruang ICU yang sedang terpasang ventilator sejumlah 18 responden. Tehnik sampling total sampling dengan kriteria penelitian ini adalah pasien cidera kepala berat dengan terpasang Ventilator, dan bersedia diteliti.

Penelitian ini menggunakan lembar observasi pasien. Prosedur penelitian ini adalah pasien yang masuk ke ruang ICU dengan cidera kepala berat yang terpasang ventilator pada hari pertama akan dilakukan penilaian saturasi oksigen, kemudian akan diobservasi selama tujuh hari dilihat apakah pasien mengalami cardiac arrest dalam jangka waktu tersebut. Uji statistic yang digunakan dalam penelitian ini adalah Spearman's rho. 


\section{HASIL}

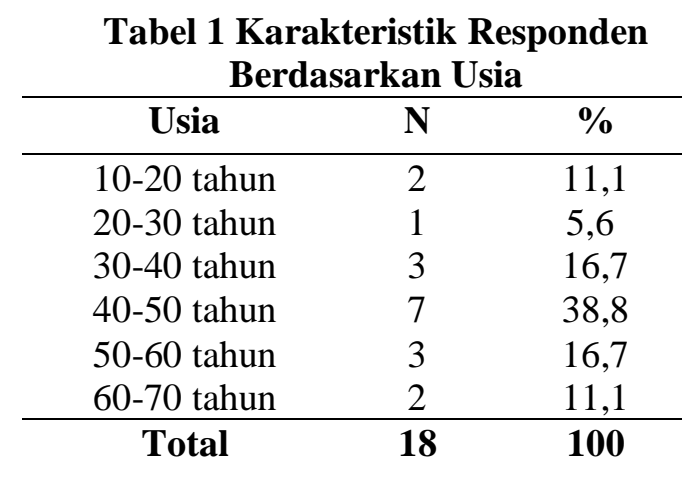

Sebagian besar responden memiliki usia 40 - 50 tahun sebanyak 7 responden $(38,8 \%)$.

Tabel 2 Karakteristik Responden Berdasarkan Jenis Kelamin

\begin{tabular}{|c|c|c|}
\hline Jenis Kelamin & $\mathbf{N}$ & $\%$ \\
\hline Laki-laki & 10 & 55,6 \\
\hline Perempuan & 8 & 44,4 \\
\hline Total & 18 & 100 \\
\hline
\end{tabular}

kelamin laki - laki sebanyak 10 responden $(55,6 \%)$.

Tabel 3 Tingkat Oksigen Dalam Darah

\begin{tabular}{lcc}
\hline \multicolumn{1}{c}{ Oksigen Dalam Darah } & $\mathbf{N}$ & $\mathbf{\%}$ \\
\hline Sangat Rendah $(<85 \%)$ & 0 & 0 \\
Rendah $(85 \%-89 \%)$ & 3 & 16,7 \\
Sedang $(90 \%-94 \%)$ & 4 & 22,2 \\
Normal (95\%-100\%) & 11 & 61,1 \\
\hline \multicolumn{1}{c}{ Total } & $\mathbf{1 8}$ & $\mathbf{1 0 0}$ \\
\hline \multicolumn{1}{c}{ Sebagian besar } & memiliki tingkat
\end{tabular}
oksigen dalam darah normal sebanyak 11 responden $(61,1 \%)$.

Tabel 4 Terjadinya Cardiac arrest

\begin{tabular}{ccc}
\hline Terjadi Cardiac arrest & N & $\%$ \\
\hline Cardiac arrest & 6 & $30 \%$ \\
Tidak Cardiac arrest & 12 & $70 \%$ \\
\hline Total & $\mathbf{1 8}$ & $\mathbf{1 0 0 \%}$ \\
\hline
\end{tabular}

Sebagian besar tidak terjadi cardiac arrest sebanyak 12 responden $(70 \%)$.
Tabel 5 Tingkat Oksigen Dalam Darah

Terhadap Terjadinya Cardiac arrest

\begin{tabular}{llcr}
\hline \multicolumn{2}{c}{ Spearman's rho } & $\begin{array}{c}\text { Oksigen } \\
\text { Dalam } \\
\text { Darah }\end{array}$ & \multicolumn{1}{c}{$\begin{array}{c}\text { Cardiac } \\
\text { arrest }\end{array}$} \\
\hline $\begin{array}{llrl}\text { Oksigen } \\
\text { Dalam }\end{array}$ & Correlation & 1.000 & .493 \\
Darah & Coefficient & & \\
& Sig. (2-tailed) &. & .035 \\
& $\mathrm{~N}$ & 18 & 18 \\
Cardiac & Correlation & .493 & 1.000 \\
arrest & Coefficient & & \\
& Sig. (2-tailed) & .035 &. \\
& $\mathrm{~N}$ & 18 & 18 \\
\hline
\end{tabular}

Tabel 5 menunjukkan nilai $\mathrm{p}=0,035$ yang berarti bahwa ada hubungan tingkat oksigen dalam darah terhadap terjadinya cardiac arrest pada pasien cidera kepala berat.

\section{PEMBAHASAN}

Hasil penelitian menjelaskan bahwa rentan usia responden terbanyak adalah pada usia 40-50 tahun sejumlah 7 responden dengan persentase sebesar $38,8 \%$, dan jumlah responden terbanyak adalah laki-laki yaitu sejumlah 10 responden dengan persentase $55,6 \%$. Berdasarkan tabel di atas tentang distribusi frekuensi tentang tingkat oksigen dalam darah pasien cidera kepala berat, didapatkan hasil bahwa sebagian besar kategori Tingkat oksigen dalam darah pasien normal yaitu sebanyak 11 responden $(61,1 \%)$, kategori sedang sebanyak 4 responden $(22,2 \%)$, kategori rendah sebanyak 3 responden (16.7\%). Berdasarkan tabel di atas tentang distribusi frekuensi cardiac arrest pasien cidera kepala berat, didapatkan hasil bahwa sebagian besar pasien tidak terjadi cardiac arrest yaitu sebanyak 12 responden (70\%) dan pasien cardiac arrest sebanyak 6 responden (30\%).

Berdasarkan tabel analisa uji statistik dengan menggunakan uji Spearman's rho, pada uji bivariat menunjukkan nilai $p$-value yang didapatkan adalah sebesar 0,035 yang berarti $p<\alpha(\alpha=0,05)$. Maka dapat disimpulkan $\mathrm{H} 1$ diterima yang artinya ada hubungan antara tingkat oksigen dalam darah terhadap terjadinya cardiac arrest pada pasien cidera kepala berat.

Menurut (Sharf, 2013), nilai Tingkat oksigen dalam darah yang normal untuk orang dewasa baik laki-laki maupun perempuan adalah 95 - 100\%. Tingkat oksigen dalam darah merupakan indikator kadar oksigen yang 
dapat diikat dan diangkut oleh darah untuk metabolisme 16 jaringan tubuh. Tingkat oksigen dalam darah yang rendah menunjukkan sebuah kondisi kurangnya oksigen di dalam darah seseorang (hipoksemia). Kondisi hipoksemia akan berakibat pasokan oksigen ke jaringan tidak adekuat, yang dapat berlanjut kepada hipoksia jaringan dan bisa mengakibatkan cardiac arrest.

Hasil penelitian (Ankita, 2015) bahwa dengan nilai tingkat oksigen dalam darah 95\%$100 \%$ akan menurunkan risiko terjadi cardiac arrest. Hal ini sesuai dengan hasil penelitian bahwa sebagian besar responden memiliki kadar oksigen dalam darah 95\%-100\% sebanyak 11 responden $(61,1 \%)$ dan sebagian besar tidak terjadi cardiac arrest sebanyak 12 responden (70\%). Sebanyak 7 responden kadar oksigen dalam darah < 95\% diantaranya 3 responden memiliki kadar oksigen dalam darah rendah (85\%-89\%) sebanyak 3 responden $(16,7 \%)$, dan kadar oksigen dalam darah sedang (90\%-94\%) sebanyak 4 responden $(22,2 \%)$, sebanyak 6 responden (30\%) mengalami cardiac arrest. Menurut (Dinsmore, 2013) Angka kehidupan yang tinggi ini dipengaruhi oleh kondisi tanda-tanda vital pasien dan juga penggunaan ventilator yang tepat. Kondisi pasien dengan cidera kepala berat yang memang memerlukan perawatan intensif yang cukup lama, perdarahan di otak menyebabkan berbagai fungsi didalam tubuh terganggu membutuhkan waktu pemulihan yang cukup lama.

Menurut (Sandroni, 2021) Tingkat oksigen dalam darah di bawah $95 \%$ atau kondisi hipoksia merupakan prediktor cardiac arrest. Hipoksemia sistemik merupakan prediktor terhadap peningkatan cardiac arrest pasien.

Hasil penelitian ini menunjukkan bahwa semakin tinggi nilai tingkat oksigen dalam darah akan meningkatkan kehidupan pasien cidera kepala berat, sebaliknya semakin rendah tingkat oksigen dalam darah akan menyebabkan cardiac arrest.

\section{KESIMPULAN}

Hasil penelitian hubungan tingkat oksigen dalam darah terhadap terjadinya cardiac arrest pasien cidera kepala berat di dapatkan hasil $p$ value $0,035<\alpha(\alpha=0,05)$ yang artinya terdapat hubungan tingkat oksigen dalam darah terhadap kejadian cardiac arrest pada pasien cidera kepala berat di RSUD Gambiran Kota Kediri.

Saran penelitian ini bagi rumah sakit diharapkan tetap meningkatkan perawatan pasien cidera kepala berat di ICU dan tetap melakukan deteksi dini dengan memanfaatkan nilai tingkat oksigen dalam darah dan menetukan tindakan dengan cepat dan tepat terhadap pasien cidera kepala berat. Bagi Institusi Pendidikan diharapkan hasil penelitian ini dapat dijadikan referensi atau wacana ilmiah yang dapat digunakan mahasiswa untuk melakukan penelitian dengan judul penelitian yang hampir sama dan variabel berbeda dengan penelitian ini. Untuk peneliti selanjutnya diharapkan penelitian ini dapat dikembangkan hasil penelitian ini dengan melihat faktor-faktor lain yang berhubungan dengan tingkat oksigen dalam darah dan cardiac arrest pasien

\section{DAFTAR PUSTAKA}

Afiani, N. Qodir, A. Widyawati, W. Purnama, I. (2021). Survival Rate Prediction of Head Injury Patients with Peripheral Oxygen Saturation. Jurnal Ilmu dan Teknologi Kesehatan, 8 (2), 115-129. doi: 10.32668/jitek.v8i2.512

Ankita, S. Kunkolol, R. Meena, S. Sangle, A.(2015). Hypoxic status and its prognosis in patients with head injury. International Journal of Medical Research \& Health Sciences, 4(3), 622. doi:10.5958/2319.5886.2015.00126.5

Dinsmore, J. (2013). Traumatic brain injury: An evidence-based review of management. Continuing Education in Anaesthesia, 13 (6) Critical Care and Pain, 189-195. doi: 10.1093/bjaceaccp/mkt010

Jiang, J. Y. (2013). Head trauma in China. Injury, 44 (11). 1453-1457. doi: 10.1016/j.injury.2012.08.045

Mauritz, W. Wilbacher, I. Majdan, M. Leitgeb, J. Janciak, I. Brazinova, A. Rusnak, M. (2008). Epidemiology, treatment and outcome of patients after severe traumatic brain injury in European 
regions with different economic status. European Journal of Public Health, 44 (11) 575-580. doi: 10.1093/eurpub/ckn079

Moppett, I. K. (2007). Traumatic brain injury: Assessment, resuscitation and early management. British Journal of Anaesthesia, 99 (1) 18-31. doi: 10.1093/bja/aem128

Sandroni, C. Cronberg, T. Sekhon, M. (2021). Brain injury after cardiac arrest: pathophysiology, treatment, and prognosis. Intensive Care Medicine, 47(12), 1393-1414. doi:10.1007/s00134-021-06548-2

Sharf, M. El Gebali, M. (2013). Correlation between Glasgow coma scale and Jugular venous oxygen saturation in severe traumatic brain injury. Egyptian Journal of Anaesthesia, 29(3), 267-272. doi:10.1016/j.egja.2013.02.008

Smith, J. Rickard, A. Wise, D. (2015, January 17). Traumatic cardiac arrest. Journal of the Royal Society of Medicine, 108(1), 11-16. doi:10.1177/0141076814560837

Trihono, N. M. (2013). Riskesdas. 1-268.

Wesson, H. Anand, R. Ferrada P. (2015). End Points of Traumatic Brain Injury Resuscitation. Current Trauma Reports, $\quad 1(3), \quad 147-154$. doi:10.1007/s40719-015-0017-8 